\title{
Abraham Flexner, la Educación Médica 113 años después
}

\author{
Abraham Flexner, Medical Education 113 years later
}

Alberto Orozco Gutiérrez*

Citar como: Orozco GA. Abraham Flexner, la Educación Médica 113 años después. Acta Med GA. 2022; 20 (1): 5-6. https://dx.doi.org/10.35366/103548

Cuando Abraham Flexner tenía 42 años, en 1908, recibió la encomienda de realizar una evaluación de la educación médica y elaborar recomendaciones para mejorarla, el resultado fue que en las 155 escuelas de medicina en 40 estados existían casi 24,000 alumnos con 3,500 profesores y 4,800 instructores, la heterogeneidad de la enseñanza fue descrita como "terrible".

El informe modificó la educación médica en el mundo, estableció destinar los dos primeros años a las ciencias básicas y los dos siguientes a la clínica. También menciona aspectos relacionados al financiamiento, a las asociaciones médicas, marcó los lineamientos de los Consejos de Certificación y de los estudios de postgrado. El avance logrado gracias al informe Flexner fue invaluable.

Ciento trece años después, y en el contexto actual, surgen dudas de nuestra educación médica.

Narro-Robles lo publicó hace 20 años "si somos honestos, tendremos que reconocer que parte de nuestra realidad, es compatible con la descripción flexneriana de hace casi cien años. Pronto tendremos que hacer algo, de hecho, pronto tendremos que hacer mucho". ${ }^{1}$

De acuerdo con el Consejo Mexicano para la Acreditación de la Educación Médica (COMAEM), en México existen 79 facultades de medicina acreditadas, tres en proceso y 51 que, aunque han explorado la posibilidad, no tienen acreditación; otras fuentes hablan de hasta 182 escuelas de medicina. ${ }^{2}$

¿Nuestras materias básicas están de acuerdo con la realidad actual?, ¿el beneficio académico a largo plazo de materias que son fácilmente olvidadas como anatomía y embriología justifica el número de horas y el costo de los laboratorios?, ¿las materias como biología molecular, informática y genética tienen un peso curricular adecuado?

¿Nuestras materias clínicas permiten un contacto con la medicina y los pacientes?, ¿permiten desarrollar destrezas de contacto, habilidades sociales y destrezas para la exploración de los pacientes, así como desarrollo de capacidad de análisis diagnóstica?

¿Nuestro internado de pregrado permite el desarrollo de habilidades que le permiten a un médico general desarrollar las competencias que se esperan de él?

El servicio social fue creado en 1936 por el Dr. Gustavo Baz con los estudiantes de medicina para "retribuir a la sociedad la deuda que contraían por haberlos educado", cabe decir que ninguna otra carrera recibió semejante reclamo.

De 1936 a 1980, los pasantes eran distribuidos entre todas las instituciones públicas del sector salud, con el paso de los años, el porcentaje asignado a la seguridad social se redujo. Para 2007, la proporción de pasantes de medicina en instituciones de seguridad social se redujo a alrededor de 3\%. Pasando casi todos a la Secretaría de Salud.

La asignación de plazas se realiza por promedio, los mejores alumnos realizan su servicio en investigación o lugares cercanos, las zonas marginadas reciben a pasante de bajos promedios que en su condición de estudiantes deben llevar a cabo funciones autorizadas solamente a médicos recibidos. La remuneración que reciben no es ni siquiera el salario mínimo y deben trabajar jornadas de cinco días y medio continuos con un día y medio de descanso.

A lo anterior se suma el hecho de que las condiciones de violencia han hecho la práctica del servicio social sumamente riesgosa. * Profesor de postgrado de Pediatría y Neonatología. Universidad Na-
cional Autónoma de México, Universidad La Salle.
Correspondencia:

Alberto Orozco Gutiérrez

Correo electrónico: orozcogutierrezalberto@gmail.com

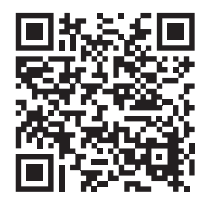


El alumno con problemas de formación deficiente pierde el último año de su formación académica en una comunidad rural, sin pago, con grandes riesgos, con nula enseñanza y posteriormente se le entrega un título, $80 \%$ de ellos van a ser rechazados para continuar su carrera como especialista, en los que realizan el servicio social rural, el porcentaje es mayor.

Desde 2004, López Bárcena publicó: "Se ubica al pasante en unidades de atención que reducen la oportunidad de aprendizaje en el primer nivel de atención y la práctica de la salud pública y privilegian las necesidades de cobertura de los servicios de salud", ${ }^{3}$ este hecho sigue siendo real.

La gran mayoría de nuestros alumnos aspiran al Examen Nacional de Aspirantes a Residencias Médicas (ENARM), porque la formación del médico general es deficiente, su reconocimiento social es nulo y sus oportunidades laborales escasas, todo esto es consecuencia de nuestro sistema de educación.

Es necesario replantear totalmente la carrera de medicina. Sin prejuicios y basados en análisis serios, evaluar el peso y la utilidad de cada una de las materias básicas, evaluar todas las materias clínicas estableciendo objetivos claros y empleando en forma ordenada y remunerada la escuela lancasteriana de enseñanza, donde el residente enseña al estudiante, verificar que el internado de pregrado proporcione las herramientas necesarias para el desarrollo profesional y el servicio social replantearlo completamente como un año académico, dejando de lado ilusiones idealistas y políticas para aprovechar la última oportunidad de lograr una adecuada enseñanza.

Como mencionó el Dr. Gustavo Nigenda desde 2013: "El papel de los pasantes podría redefinirse para permitirles apoyar en estas tareas bajo un modelo operativo basado en la acción responsable y de calidad y no en el castigo innecesario que representa hoy la forma en la que miles de ellos son obligados a participar". ${ }^{4}$

Es indispensable reflexionar sobre la necesidad de formar buenos médicos generales como lo menciona el Dr. Narro: "A la sociedad se le debe asegurar en todo momento que quien practica la medicina en cualquier etapa de su vida profesional es capaz y competente, que tiene los conocimientos, las habilidades y la actitud necesaria para fungir como médico".

\section{REFERENCIAS}

1. Narro-Robles J. III. La herencia de Flexner. Las ciencias básicas, el hospital, el laboratorio, la comunidad. Gac Med Mex. 2004; 140 (1): 52-55.

2. Consejo Mexicano para la acreditación de la educación médica. A.C. Estatus de la Acreditación Nacional Disponible en: http://www. comaem.org. $\mathrm{mx} /$ ?page_id $=76$

3. López BJJ, González COMMG, Velasco MM. Servicio Social de Medicina en México. Factibilidad del cumplimiento académico en el área rural. Rev Fac Med UNAM. 2004; 47 (5): 181-186.

4. Nigenda G. Servicio social en medicina en México. Una reforma urgente y posible. Salud Pública Méx. 2013; 55 (5): 519-527. 